\title{
PERSPEKTIF PENGAMBIL KEBIJAKAN DAN STRATEGI PENGEMBANGAN \\ TANAMAN OBAT ASLI LAMPUNG \\ BERDASARKAN PERSEPSI PEMERINTAH \\ PROVINSI LAMPUNG
}

(KAJIAN PENGEMBANGAN TAMAN HERBAL DI PROVINSI LAMPUNG TAHUN 2017)

POLICY OF PERSPECTIVE AND DEVELOPMENT STRATEGY

ORIGINAL DRUG LAMPUNG BASED ON PERCEPTION

GOVERNMENT PROVINCE LAMPUNG

(THE STUDY OF HERBAL PARK DEVELOPMENT IN LAMPUNG PROVINCE ON 2017)

\author{
Henita Astuti ${ }^{1}$, Ratna Dewi Judhaswati ${ }^{2}$, M. Syafrizal ${ }^{1}$, Jekvy Hendra ${ }^{3}$, Azhari Rangga ${ }^{4}$ \\ ${ }^{1}$ Peneliti Balitbangda Provinsi Lampung \\ ${ }^{2}$ Peneliti Balitbangda Provinsi Jawa Timur \\ ${ }^{3}$ Peneliti Balai Pengkajian Teknologi Pertanian Lampung \\ ${ }^{4}$ Akademisi Fakultas Pertanian Universitas Lampung \\ email: henitaastuti@gmail.com
}

\begin{abstract}
Indigenous Medicinal Plants Lampung (TOAL) is a medicinal plant obtained directly from natural ingredients in all regions in Lampung Province. The local government effort and local policy in developing and preserving it is necessary. The purpose of this research is to know the policy of perspective and strategy of TOAL development based on perception of policy maker in Lampung Province. The study was conducted from May to September 2017 located in Lampung Province. Respondents were determined by purposive sampling by appointing relevant parties on TOAL development activities. The results showed that Internal Factor, the strength among others the use of medicinal plants as an alternative medicine has become a tradition of Lampung society, The weakness factor among others HR is still less creative to create variants of traditional medicine products. External Factors consist of opportunities that can be marketed in the form of processed products that can be marketed domestic scale and national scale; and threats, funds allocated to support the development of TOAL are still limited. Strategy for Developing and Implementing Traditional Medicine and Planning Systems for the Availability of Traditional Medicines Raw Materials in Lampung Province to become National Policy Direction to Support Traditional Health Services, covering a) Cultivation and conservation of TOAL resources, b) efficacy and benefits, c) quality, d) accessibility , e) appropriate use, $f$ ) supervision, $g$ ) research and development, $h$ ) documentation and databases, i) human resource development and j) monitoring and evaluation.
\end{abstract}

Keywords: Medicinal plants, the policy of perspective, development strategies, policies

\section{PENDAHULUAN}

Di belahan dunia, pembuat kebijakan, profesional kesehatan dan masyarakat bergumul dengan isu-isu mengenai keamanan, efektivitas, kualitas, ketersediaan, pelestarian dan pengaturan program kesehatan tradisional atau obat pelengkap, yang terus menerus digunakan secara luas di sebagian besar negara, dan serapannya meningkat pesat di negara lain. Pada saat bersamaan, ketertarikan masyarakat luas terhadap obat tradisional (Traditional Medicine) berkembang melampaui produk kimia untuk dipusatkan pada praktik dan praktisi pengobatan (WHO, 2013).

Dalam Executif Summary buku World Health Organization-Traditional Medicine Strategy 2014-2023, dikutif bahwa obat tradisional (Traditional Medicine selanjutnya disebut TM) adalah bagian yang penting dan sering diremehkan di bidang pelayanan kesehatan saat ini. Sebaliknya, di beberapa negara, obat tradisional atau obat non konvensional bisa disebut 
sebagai obat pelengkap (Complement Medicine). TM memiliki sejarah panjang dari segi khasiat karena memberi kemanfaatan, dapat digunakan dalam perawatan kesehatan, untuk pencegahan bahkan dapat direkomendasikan untuk pengobatan penyakit, terutama untuk penyakit kronis.

Melalui buku Traditional Medicine Strategy 2014-2023, WHO menghimbau dengan mendukung negara-negara anggota untuk : 1) memanfaatkan potensi tanaman tradisional di setiap daerah untuk dikontribusikan pada layanan kesehatan tradisional bagi masyarakat yang membutuhkan, 2) mempromosikan penggunaan obat tradisonal sebagai bahan alami yang aman dan efektif, 3) perlu dukungan regulasi terhadap bidang penelitian dan pengembangan khusus produk berbasis obat tradisional dengan cara mengintegrasikan bahan obat tradisional, pelaku pengobatan tradisonal (Etnomedisin) dan penderita yang percaya akan khasiatnya, 4) melakukan pengaturan dan penetapan kebijakan terkait tradisonal medicine terintegrasi dalam bidang perawatan kesehatan nasional, 5) menjaga kualitas dan keamanan produk, terutama dalam penyediaan bahan baku yang berkualitas dan perlu mengetahui efek khasiat kemanjuran obat tersebut, 6) menyediakan anggaran untuk pelatihan dan pendidikan teknisi / petugas bidang $a k u$ presure dari Pusat Kesehatan, serta 7) menyebarluaskan informasi tentang kebijakan nasional/ daerah, peraturan, profil layanan kesehatan, dan data penelitian agar dapat memberikan sumber data yang objektif bagi masyarakat luas.

Tanaman Obat Asli Lampung atau disingkat TOAL adalah tanaman obat yang didapat langsung dari bahan-bahan alamiah di seluruh daerah se Provinsi Lampung, terolah secara sederhana atas dasar pengalaman dan dipergunakan dalam pengobatan tradisional (Almos dan Pramono, 2015). Kebijakan daerah dalam mengembangkan dan melestarikan TOAL ini sangatlah diperlukan. Oleh karena itu diperlukan suatu penelitian untuk melihat bagaimana persepsi para pengambil kebijakan terhadap pengembangan dan kelayakan usaha TOAL ini.

Dalam Undang-Undang Nomor 36 Tahun 2009 tentang Kesehatan, tertuang pada Pasal 48 yang berbunyi : Pelayanan Kesehatan Tradisional merupakan salah satu bagian dari 17 upaya pelayanan kesehatan yang harus tersedia dalam fasilitas pelayanan kesehatan secara terpadu dan berkesinambungan. Hal ini diperkuat lagi dengan ditetapkannya Peraturan Pemerintah Nomor
103 Tahun 2014 tentang Pelayanan Kesehatan Tradisonal.

Arah Kebijakan Kementerian Kesehatan Tahun 2015-2019 yaitu Penguatan Pelayanan Kesehatan Primer di Puskesmas; Penerapan Pendekatan Berkelanjutan dimana Pelayanan Mengikuti Siklus Hidup Manusia dan Intervensi Berbasis Risiko Kesehatan (Gambar 1.).

Mendukung Visi Direktorat Jenderal Pelayanan Kesehatan: "Akses Pelayanan Kesehatan yang Terjangkau dan Berkualitas bagi Masyarakat, yang dijalankan untuk meningkatkan mutu pelayanan masyarakat melalui upaya peningkatan pengendalian kinerja, anggaran dan manajemen kinerja di lingkungan Pemerintah Provinsi Lampung."

Dipandang perlu menyelaraskan dengan visi Direktorat Pelayanan Kesehatan Tradisional: "Menuju Pelayanan Kesehatan Tradisonal yang setara dengan Pelayanan Konvensional" yang digerakkan dengan misi "Mewujudkan Pelayanan Kesehatan Tradisonal yang Aman, Bermanfaat, dan dapat Dipertanggungjawabkan."

Penelitian-penelitian terkait tanaman obat sudah banyak dilakukan, diantaranya: Ajani dan Ogunbiyi (2015), Ttipathi et. al. (2011), Juarez-Rojop (2012). Penelitian-penelitian tersebut mengungkapkan bahwa adanya tanaman-tanaman obat tersebut bermanfaat untuk kesehatan. Penelitian terkait kebijakan pemerintah dalam pengembangan tanaman obat masih terbatas. Penelitian ini bertujuan untuk mengetahui persepsi stakeholder pada tanaman obat di Provinsi Lampung.

Tujuan penelitian ini adalah menjelaskan persepsi pengambil kebijakan dalam pengembangan komoditas tanaman obat. Penelitian ini bermanfaat dalam pengambilan kebijakan pengembangan obat di level pemerintah Propinsi. 


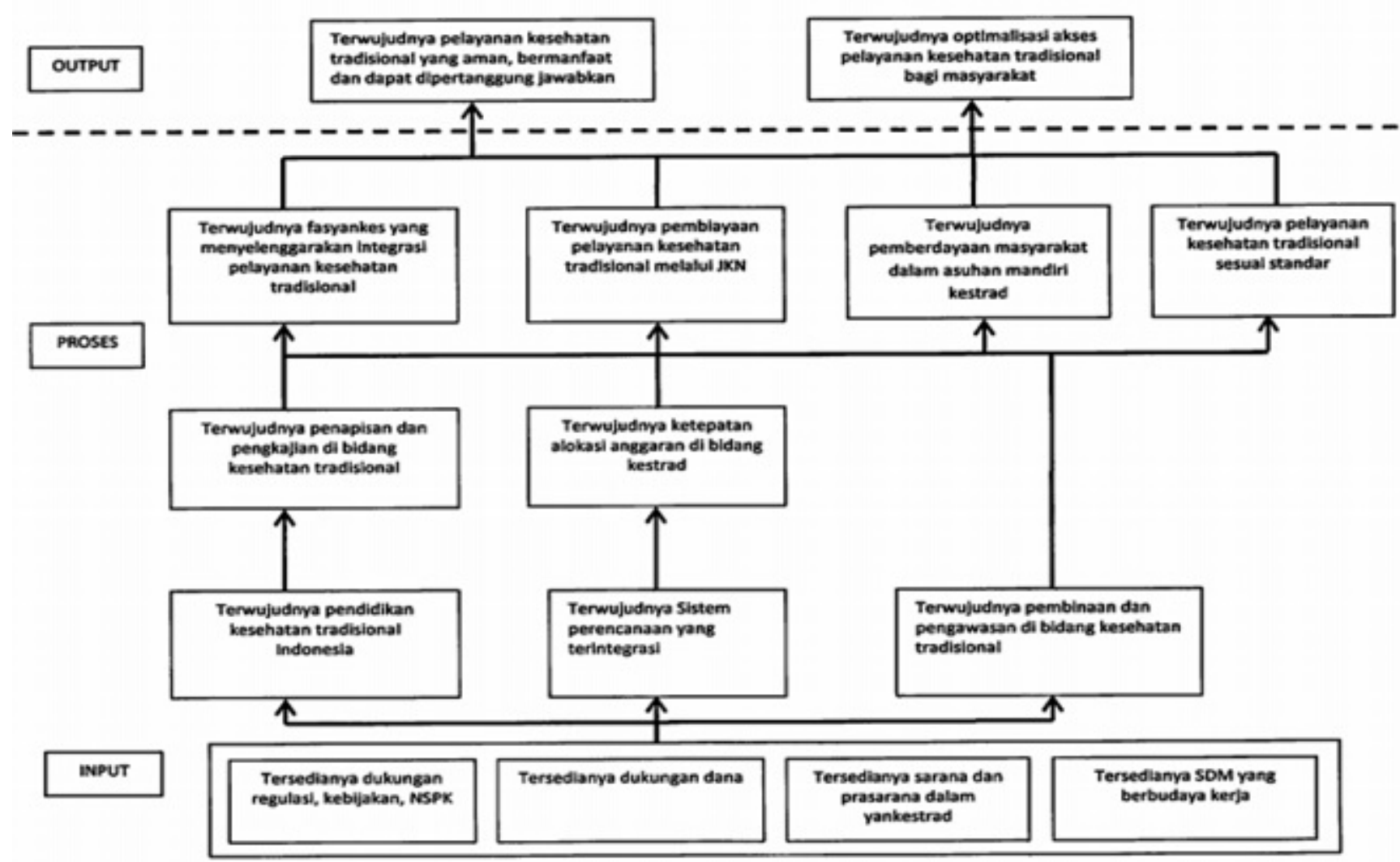

Sumber: Rencana Aksi Kegiatan Direktorat Pelayanan Kesehatan Tradisonal Tahun 2015-2019

Gambar 1. Roadmap Rencana Strategis Pelayanan Kesehatan Tradisonal

\section{METODE PENELITIAN}

Penelitian ini menggunakan metode deskriptif kualitatif dan pengumpulan data dalam penyusunan dokumen ini menggunakan data primer maupun data sekunder. Data primer dengan melakukan wawancara mendalam dimana yang menjadi informannya adalah para pengambil kebijakan di Provinsi Lampung, sedangkan data sekunder dikumpulkan melalui studi literatur yang mengutip hasil penelitian dari beberapa sumber.

Waktu penelitian dimulai bulan Mei sampai dengan September 2017 berlokasi di Provinsi Lampung. Alat analisis yang digunakan adalah analisis diskriptif dan analisis SWOT (Strentgth, Weakness, Opportunity, dan Threath)..

\section{Analisis Data}

Pengolahan dan analisis data yang dilakukan adalah sebagai berikut:

1. Sampel diambil secara purposive sampling pada 50 (lima puluh) orang sebagai pengambil kebijakan di Provinsi Lampung.

2. Metode yang digunakan berdasarkan deskriptif kualitatif non grounded, yaitu wawancara mendalam yang dikaji secara kuantitatif, untuk mengetahui prospek pengembangan Tanaman Obat di Provinsi Lampung.

3. Mencari dan merumuskan alternatif strategi pengembangan tanaman obat asli Lampung menggunakan matriks SWOT. Matriks SWOT dapat menggambarkan secara jelas hubungan antara faktor internal (kekuatan dan kelemahan) maupun eksternal (peluang dan ancaman) dari berbagai aspek sesuai persepsi pengambil kebijakan dan selanjutnya masalah diselesaikan dengan mengidentifikasi kekuatan dan kelemahan yang dimiliki (Rangkuti, 2006) dapat dilihat pada Tabel 1. 
Tabel 1. Matriks SWOT

\begin{tabular}{|c|c|c|}
\hline & Kekuatan (S) & Kelemahan (W) \\
\hline \multirow[t]{2}{*}{ Peluang (O) } & Strategi SO & Strategi WO \\
\hline & $\begin{array}{l}\text { Gunakan kekuatan untuk memanfaatkan } \\
\text { peluang }\end{array}$ & $\begin{array}{l}\text { Atasi kelemahan dengan meman- } \\
\text { faatkan peluang }\end{array}$ \\
\hline \multirow[t]{2}{*}{ Ancaman (T) } & Strategi ST & Strategi WT \\
\hline & $\begin{array}{l}\text { Gunakan kekuatan untuk menghindari } \\
\text { ancaman }\end{array}$ & $\begin{array}{l}\text { Meminimalkan kelemahan dan } \\
\text { menghindari ancaman }\end{array}$ \\
\hline
\end{tabular}

Matrik SWOT merupakan perangkat pencocokan penting untuk mengembangkan 4 (empat) tipe strategi yaitu strategi SO (Strenght-Opportunities), strategi W O (Weakness-Opportunities), strategi ST (Strenght-Threats) dan strategi WT (Weakness-Threats) . Tujuan dari setiap perangkat kecocokan untuk menghasilkan strategi pengembangan tanaman obat asli Lampung mendukung Program Pengembangan Taman Herbal di Provinsi Lampung.

\section{HASIL DAN PEMBAHASAN Data Responden}

Responden ditentukan secara purposive sampling atau disengaja dengan menunjuk pihak-pihak yang terkait pada kegiatan pengembangan tanaman obat asli Lampung, mulai dari Dinas/Lembaga teknis; Lembaga Penelitian dan Pengembangan; Lembaga yang nantinya menangani perencanaan dan pembangunan terkait kegiatan yang sedang diteliti jika memungkinkan dapat ditindaklanjuti; Perguruan Tinggi baik negeri maupun swasta untuk melihat sejauhmana produk yang dihasilkan yang berasal dari tanaman obat asli Lampung dapat dikenalkan dikalangan masyarakat dan mahasiswa pada khususnya; Lembaga swasta yang menangani perdagangan dan industri; Perbankan; sampai Lembaga yang mengeluarkan perizinan agar produk yang berasal dari tanaman obat asli Lampung ini dapat beredar resmi di Provinsi Lampung maupun dipasarkan di luar daerah secara nasional maupun internasional. Adapun data responden dapat dilihat pada Tabel 2.

Hasil penelitian yang berupa angka-angka didiskripsikan agar lebih memberikan manfaat dan gambaran mengenai subjek penelitian. Dari rencana 50 responden hanya terkumpul data 27 orang, 23 orang lainnya yang diharapkan dapat memberikan masukan terhadap penelitian ini, ternyata mempunyai alasan yang beragam antara lain : tidak ditempat, belum merasa menjadi pihak terkait, dan belum menjadi peran dan tugas pokok fungsinya sebagai pengambil kebijakan sehingga kuesioner tidak terisi.

\section{Karakteristik Responden}

Data yang diperoleh dari penelitian yang telah dilakukan dapat dilihat pada Tabel 2, responden pria berjumlah $64 \%$ lebih banyak daripada wanita.

Penelitian dilakukan dengan cara mendatangi responden ke Lembaga atau Instansi masing-masing oleh petugas Enumerator dengan cara mewawancarai, namun karena berbagai kesibukan responden, bahan kuesioner ditinggal untuk diisi kemudian diambil kembali oleh Enumerator pada waktu yang telah ditentukan. Responden dipilih berdasarkan pandangan sebagai pihak-pihak yang terkait dan diharapkan dapat berkontribusi ikut mengembangkan kegiatan pegembangan tanaman obat asli Lampung kedepan.

Batasan umur pada penelitian ini antara 30 tahun sampai dengan 60 tahun. Berdasarkan Tabel 3, karakteristik usia responden dari penelitian ini dimulai dari yang paling tinggi yaitu range 40 - 49 tahun sebanyak $52 \%$, range 50 - 59 tahun sebanyak $40 \%$ dan sisanya $8 \%$ dari range umur 30 - 39 tahun.

Faktor-faktor yang berhubungan dengan pengetahuan responden tentang pengembangan tanaman obat asli Lampung meliputi pendidikan dan pekerjaan maupun jabatan yang melekat. Pendidikan merupakan salah satu pengaruh terhadap tingkat daya tangkap informasi, sikap, pengetahuan dan teknologi yang dikuasai. Oleh karena itu pendidikan responden perlu diketahui (Istaminingdiyah, 2008 dalam Hidayati dan Perwitasari, 2011).

\section{Faktor Internal}

Dari hasil penelitian yang disajikan pada Tabel 4. Berdasarkan faktor internal membuktikan kekuatan penggunaan tanaman obat sebagai obat alternatif sudah membudaya atau telah 
menjadi tradisi masyarakat Lampung dinyatakan sebagai rating tertinggi sebanyak $40 \%$ dari responden; $52 \%$ responden menyatakan pangsa pasar untuk kalangan menengah ke bawah; $48 \%$ responden menyatakan bahwa sumber daya manusia (SDM) dibidang tanaman obat mulai dapat disediakan dari masyarakat Lampung, yang dibuktikan beberapa perguruan tinggi negeri dan swasta maupun politeknik telah menyediakan kurikulum tentang kesehatan tradisional dan jurusan farmasi; $44 \%$ responden menyatakan bahan baku tanaman obat melimpah di Lampung.

Faktor kelemahan juga merupakan bagian dari faktor internal. Dari hasil penelitian dibuktikan bahwa walaupun SDM melimpah tapi responden menyatakan $60 \%$ SDM masih kurang kreatif menciptakan varian produk obat tradisional; $72 \%$ responden menyatakan teknologi produksi masih sangat sederhana cenderung manual; pendidikan tentang kesehatan tradisional yang diaplikasikan khusus di bidang produksi tanaman obat masih rendah, umumnya $60 \%$ responden menyatakan belum diaplikasikan dengan serius; $80 \%$ responden menyatakan pengelolaan usaha tanaman obat mulai dari budidaya sampai proses pengolahan belum mengikuti Standar Operasional Prosedur (SOP) sesuai standar penggunaan bahan alam yang dipersyaratkan; dan $36 \%$ responden menyatakan masyarakat masih mengalokasikan modal sendiri sehingga kapasitas produksi juga terbatas.

\section{Faktor Eksternal}

Hasil penelitian berdasarkan faktor eksternal (Tabel 5.), 60\% responden menyatakan peluang dapat dipasarkan dalam bentuk produk olahan yang dapat dipasarkan skala domestik maupun skala nasional; $48 \%$ responden menyatakan pemerintah siap berperan sebagai regulasi untuk mendukung pengembangan tanaman obat asli Lampung melalui alokasi ke pusat-pusat kesehatan mulai dari desa (puskesmas); 68\% responden menyatakan metode ini dapat memenuhi kebutuhan masyarakat khususnya ditingkat menengah ke bawah sebelum direkomendasikan penggunaan obat medis yang umumnya masih impor terkadang tidak tersedia; $56 \%$ pendapat responden bahwa pemerintah dapat menyiapkan tenaga kesehatan khusus untuk mencukupi kebutuhan di kalangan masyarakat, dapat berperan sebagai kader asuhan mandiri (asman) maupun petugas-petugas yang menguasai bidang akupresure; dan $48 \%$ dinyatakan responden jika teknis produksi memadai dapat mendorong peralihan konsumsi obat medis ke obat alternatif, sehingga masalah-masalah kesehatan dan solusi obat dapat terpecahkan. 
Tabel 2. Data Responden Pengambil Kebijakan di Provinsi Lampung

\begin{tabular}{|c|c|c|c|c|}
\hline No & Instansi & Lembaga/Bidang & Nama Responden & Jabatan \\
\hline 1 & Universitas Lampung & Unila & Dr. Kuswanto F.H. & Wakil Dekan III \\
\hline 2 & Politeknik Negeri Lampung & Polinela & Ir. Hilman Hidayat, M.Si & Fungsional Dosen \\
\hline 3 & Universitas Tulang Bawang & Prodi Farmasi & Lilik Koernia W, S.Farm, MPH. & Ketua Program Studi \\
\hline 4 & Politeknik Kesehatan Negeri & Poltekes & I Nyoman Mudana, M.Kes & Kasubbag Adum \\
\hline 5 & Universitas Bandar Lampung & Ekonomi dan Bisnis & - & - \\
\hline 6 & Biro Perekonomian & Biro Ekonomi & - & - \\
\hline 7 & BPTP Lampung & Kerjasama dan Pelayanan Teknis & Arfi Irawati, M.Si & Kepala Seksi \\
\hline 8 & BPTP Lampung & Widyaiswara & Ir. Bambang Haryanto, M.Si & F. WI Madya \\
\hline 9 & KADIN Lampung & KADIN & Drs. Sarifuddin & Sekretaris Eksekutif \\
\hline 10 & BPOM Lampung & Serlik & Tri Suyarto, Apt. & Kepala Bidang \\
\hline 11 & Bappeda Prov. Lampung & Ekonomi & - & - \\
\hline 12 & Bappeda Prov. Lampung & Pertanian & - & - \\
\hline 13 & Dinas TPH Prov & UPTD Penyuluhan & Ir. Dewi Susanti, MP. & Kepala Bidang \\
\hline 14 & Dinas TPH Prov & Perencanaan & Amalia Riskiyanti, S.Si. M.M. & Kasubbag \\
\hline 15 & Dinas TPH Prov & Alsintan, Pupuk, Pestisida & Ir. Sugiarti, MM. & Kepala Seksi \\
\hline 16 & Dinas TPH Prov & Kasi Bud.Sayuran,Tanaman Obat & Ir. Suhendra Arsol & Kepala Seksi \\
\hline 17 & Dinas Kesehatan Prov & Pelayanan Kesehatan & Uki Basuki, M.Kes. & Kepala Bidang \\
\hline 18 & Dinas Kesehatan Prov. & Kesehatan Tradisional & Imam Thamrin, M.Kes & Kasi Kestra \\
\hline 19 & Dinas Perdagangan Prov. & Umum & Resty Yunise Prima, S.Pd. MM. & PLH Kanbag Umum \\
\hline 20 & Dinas Perindustrian Prov. & Fungsional & Yunani, A.Md. & Fungsional \\
\hline 21 & Dinas Koperasi dan UMKM & UMKM & - & - \\
\hline 22 & Balitbangda Prov Lampung & Ekonomi Pembangunan & Dr. Sukismanto, Aji, M.Si & Kepala Bidang \\
\hline 23 & Balitbangda Prov Lampung & Penerapan Iptek & Dr. A. Zoelkarnaen R, STM. Sip & Kepala Bidang \\
\hline 24 & Balitbangda Prov. Lampung & SosBud dan Kemasyarakatan & - & - \\
\hline 25 & Balitbangda Prov. Lampung & Peneliti & Ridwan Saefuddin, SE. M.Si & F. Peneliti Muda \\
\hline 26 & Balitbangda Prov Lampung & Keuangan & Yanthi Riswulan, SP. & Kasubid \\
\hline 27 & Balitbangda Prov. Lampung & Perencanaan & Andi Mulya, SSTTP. MM & Kasubid \\
\hline 28 & Balitbangda Prov Lampung & Umum dan Kepegawaian & Prayudi Ari Wibowo, SH. & Kasubid \\
\hline 29 & Bank Indonesia & Ekonomi & - & - \\
\hline 30 & Bank Lampung & Permodalan & - & - \\
\hline 31 & Bappeda Kab. Lampung Utara & Ekonomi & Anom Sauni, SH. MH. & Kepala Bidang \\
\hline 32 & Dinas Pertanian Kab. L. Utara & Produksi & Ir. Yusmaniah & Kasi \\
\hline 33 & Dinas Kesehatan L. Utara & Pelayanan Kesehatan & Listiono, M.Kes. & Kepala Seksi \\
\hline 34 & Puskesmas Abung Semuli L.U & Puskesmas Contoh & dr. May Madinah & Kepala Puskesmas \\
\hline 35 & Balitbangda Kab. L. Tengah & Ekonomi & - & - \\
\hline 36 & DinKes Kab. L. Tengah & Pelayanan Kesehatan & - & - \\
\hline 37 & Disperta Kab. L. Tengah & Produksi & - & - \\
\hline 38 & Puskesmas Seputih Raman & Puskesmas Contoh & - & - \\
\hline 39 & Bappeda Kab. L.Timur & Ekonomi & - & - \\
\hline 40 & DinKes Kab. L. Timur & Pelayanan Kesehatan & - & - \\
\hline 41 & DisPerta Kab. L. Timur & Produksi & - & - \\
\hline 42 & Bappeda Kota Metro & Ekonomi & - & - \\
\hline 43 & Dinas TPH Kota Metro & Pangan, Hortikultura, Kehutanan & Wiji, SP. & Kepala bidang \\
\hline 44 & Dinas Kesehatan & Pelayanan Kesehatan & - & - \\
\hline 45 & Puskesmas Contoh & Puskesmas Contoh & - & - \\
\hline 46 & Bappeda Kota Bd. Lampung & Ekonomi & - & - \\
\hline 47 & DinKes Kota Bd. Lampung & Pelayanan Kesehatan & - & - \\
\hline 48 & DisPerta Kota Bd. Lampung & Produksi & - & - \\
\hline 49 & Puskesmas Pasar Ambon & Puskesmas Contoh & - & - \\
\hline 50 & Puskesmas Sukaraja & Puskesmas Contoh & - & - \\
\hline
\end{tabular}

Sumber : Data Primer, 2017. 
Tabel 3. Karakteristik responden dari kalangan pengambil kebijakan di kalangan Pemerintah Provinsi Lampung

\begin{tabular}{llcc}
\hline & Karakteristik & Jumlah & Responden (\%) \\
\hline Jenis Kelamin & Pria & 18 & 64 \\
& Wanita & 9 & 36 \\
& Total & $\mathbf{2 7}$ & $\mathbf{1 0 0}$ \\
\hline Usia & $20-29$ & 0 & 0 \\
& $30-39$ & 2 & 8 \\
& $40-49$ & 15 & 52 \\
& $50-59$ & 10 & 40 \\
& $>60$ & 0 & 0 \\
& Total & $\mathbf{2 7}$ & $\mathbf{1 0 0}$ \\
\hline Pendidikan & SMA & & 32 \\
& S1 & 8 & 56 \\
& S2 & 16 & 12 \\
& S3 & 3 & $\mathbf{1 0 0}$ \\
\hline Total & PNS & $\mathbf{2 7}$ & 92 \\
& Karyawan Swasta & 24 & 8 \\
& Total & 3 & $\mathbf{1 0 0}$ \\
\hline Jabatan & Kepala Instansi & $\mathbf{2 7}$ & 0 \\
& Kepala Bidang setara & 0 & 32 \\
& Kasi/Kasubbag/ bid. Setara & 9 & 52 \\
& Fungsional & 13 & 16 \\
& Total & 57 & $\mathbf{1 0 0}$ \\
\hline
\end{tabular}

Sumber : Data Primer, 2017.

Hasil penelitian yang disajikan dari faktor ekternal yang merupakan ancaman, 36\% responden menyatakan dana yang dialokasikan untuk mendukung pengembangan tanaman obat asli Lampung masih terbatas, hal ini dibuktikan dengan minimnya anggaran untuk alokasi kegiatan-kegiatan sejenis baik pada dinas teknis yang mengawal bidang budidaya sampai prosesing (Dinas Lingkup Pertanian dan Perindustrian), yang mengatur alokasi penggunaan umumnya dikalangan masyarakat (Dinas Kesehatan dan leading sektor ke bawah) maupun yang mengurus perizinan dan standardisasi melalui sosialiasi, pembinaan dan pengawasan (Dinas Perdagangan dan BBPOM); $68 \%$ pendapat responden belum signifikan persaingan produksi maupun pemasaran produk obat tradisional yang berasal dari daerah Lampung sendiri, namun sebaliknya produk banyak berasal dari daerah lain yang SOP perizinan terstandar sehingga jika dibiarkan dapat mematikan bisnis produk obat tradisional dalam daerah yang pada kenyataannya cukup sulit mengakses perizinan dari Balai Besar Pengawasan Obat dan Makanan (BBPOM); salah satu penyebab sulitnya mengakses perizinan (menurut pengakuan $48 \%$ responden) bagi masyarakat yang mengembangkan usaha produksi obat tradisional umumnya dikarenakan kualitas produk maupun bahan baku masih rendah, serta rumah produksi belum memadai, hal ini dinyatakan oleh responden sebanyak $60 \%$. 
Tabel 4. Rating Faktor Internal Berdasarkan Persepsi Pengambil Kebijakan Mendukung Pengembangan Taman Herbal di Provinsi Lampung

\begin{tabular}{|c|c|c|c|c|}
\hline \multirow{2}{*}{ No } & \multirow{2}{*}{ Rating Faktor Eksternal } & \multirow{2}{*}{$\begin{array}{c}\text { Rating berdasarkan } \\
\text { bobot }\end{array}$} & \multicolumn{2}{|c|}{ Responden } \\
\hline & & & Jumlah & Persentase (\%) \\
\hline \multirow[t]{6}{*}{1} & KEKUATAN & & & \\
\hline & Sudah membudaya/ tradisi & Sangat Tinggi & 5 & 20 \\
\hline & masyarakat & Tinggi & 11 & 40 \\
\hline & & Rendah & 10 & 36 \\
\hline & & Sangat rendah & 1 & 4 \\
\hline & & Total & 27 & 100 \\
\hline \multirow[t]{5}{*}{$\mathrm{b}$} & Pangsa Pasar & Sangat Tinggi & 5 & 16 \\
\hline & Menengah ke bawah & Tinggi & 13 & 52 \\
\hline & & Rendah & 9 & 32 \\
\hline & & Sangat rendah & 0 & 0 \\
\hline & & Total & 27 & 100 \\
\hline \multirow[t]{5}{*}{$\mathrm{c}$} & Tenaga Kerja Memadai & Sangat Tinggi & 5 & 16 \\
\hline & & Tinggi & 12 & 48 \\
\hline & & Rendah & 7 & 24 \\
\hline & & Sangat rendah & 3 & 12 \\
\hline & & Total & 27 & 100 \\
\hline \multirow[t]{5}{*}{ d } & Bahan Baku Melimpah & Sangat Tinggi & 7 & 28 \\
\hline & & Tinggi & 12 & 44 \\
\hline & & Rendah & 6 & 20 \\
\hline & & Sangat rendah & 2 & 8 \\
\hline & & Total & 27 & 100 \\
\hline 2 & KELEMAHAN & & & \\
\hline \multirow[t]{5}{*}{$\mathrm{a}$} & SDM kurang kreatif & Sangat Tinggi & 7 & 28 \\
\hline & & Tinggi & 17 & 60 \\
\hline & & Rendah & 3 & 12 \\
\hline & & Sangat rendah & 0 & 0 \\
\hline & & Total & 27 & 100 \\
\hline \multirow[t]{5}{*}{$\mathrm{b}$} & Teknologi sederhana & Sangat Tinggi & 6 & 24 \\
\hline & & Tinggi & 18 & 72 \\
\hline & & Rendah & 3 & 4 \\
\hline & & Sangat rendah & 0 & 0 \\
\hline & & Total & 27 & 100 \\
\hline \multirow[t]{5}{*}{$\mathrm{c}$} & Pendidikan rendah & Sangat Tinggi & 3 & 12 \\
\hline & & Tinggi & 15 & 60 \\
\hline & & Rendah & 9 & 28 \\
\hline & & Sangat rendah & 0 & 0 \\
\hline & & Total & 27 & 100 \\
\hline \multirow[t]{5}{*}{ d } & Manajemen rendah & Sangat Tinggi & 2 & 8 \\
\hline & & Tinggi & 22 & 80 \\
\hline & & Rendah & 3 & 12 \\
\hline & & Sangat rendah & 0 & 0 \\
\hline & & Total & 27 & 100 \\
\hline \multirow[t]{5}{*}{$\mathrm{e}$} & Modal terbatas & Sangat Tinggi & 8 & 32 \\
\hline & & Tinggi & 11 & 36 \\
\hline & & Rendah & 7 & 28 \\
\hline & & Sangat rendah & 1 & 4 \\
\hline & & Total & 27 & 100 \\
\hline
\end{tabular}

Sumber : Data Primer, 2017. 
Tabel 5. Rating Faktor Eksternal Berdasarkan Persepsi Pengambil Kebijakan Mendukung Pengembangan Taman Herbal di Provinsi Lampung

\begin{tabular}{|c|c|c|c|c|}
\hline \multirow{2}{*}{ No } & \multirow{2}{*}{ Rating Faktor Eksternal } & \multirow{2}{*}{$\begin{array}{c}\text { Rating berdasarkan } \\
\text { bobot }\end{array}$} & \multicolumn{2}{|c|}{ Responden } \\
\hline & & & Jumlah & Persentase (\%) \\
\hline \multirow[t]{6}{*}{1} & PELUANG & & & \\
\hline & Pasar dan Pemasaran & Sangat Tinggi & 4 & 16 \\
\hline & & Tinggi & 17 & 60 \\
\hline & & Rendah & 6 & 24 \\
\hline & & Sangat rendah & 0 & 0 \\
\hline & & Total & 27 & 100 \\
\hline \multirow[t]{5}{*}{$\mathrm{b}$} & Regulasi Pemerintah & Sangat Tinggi & 3 & 12 \\
\hline & & Tinggi & 12 & 48 \\
\hline & & Rendah & 11 & 36 \\
\hline & & Sangat rendah & 1 & 4 \\
\hline & & Total & 27 & 100 \\
\hline \multirow[t]{5}{*}{$\mathrm{c}$} & Kebutuhan Masyarakat Kelas & Sangat Tinggi & 6 & 16 \\
\hline & Bawah & Tinggi & 17 & 68 \\
\hline & & Rendah & 4 & 16 \\
\hline & & Sangat rendah & 0 & 0 \\
\hline & & Total & 27 & 100 \\
\hline \multirow[t]{5}{*}{ d } & SDM Tenaga Kerja & Sangat Tinggi & 8 & 28 \\
\hline & & Tinggi & 15 & 56 \\
\hline & & Rendah & 4 & 16 \\
\hline & & Sangat rendah & 0 & 0 \\
\hline & & Total & 27 & 100 \\
\hline \multirow[t]{5}{*}{$\mathrm{e}$} & Teknis Produksi memadai & Sangat Tinggi & 2 & 8 \\
\hline & & Tinggi & 12 & 48 \\
\hline & & Rendah & 12 & 40 \\
\hline & & Sangat rendah & 1 & 4 \\
\hline & & Total & 27 & 100 \\
\hline 2 & ANCAMAN & & & \\
\hline \multirow[t]{5}{*}{$\mathrm{a}$} & Dana Terbatas & Sangat Tinggi & 11 & 36 \\
\hline & & Tinggi & 8 & 32 \\
\hline & & Rendah & 7 & 28 \\
\hline & & Sangat rendah & 1 & 4 \\
\hline & & Total & 27 & 100 \\
\hline \multirow[t]{5}{*}{$\mathrm{b}$} & Persaingan dari daerah lain & Sangat Tinggi & 2 & 0,08 \\
\hline & & Tinggi & 6 & 24 \\
\hline & & Rendah & 17 & 68 \\
\hline & & Sangat rendah & 2 & 8 \\
\hline & & Total & 27 & 100 \\
\hline \multirow[t]{5}{*}{$\mathrm{c}$} & Kualitas rendah & Sangat Tinggi & 6 & 16 \\
\hline & & Tinggi & 15 & 60 \\
\hline & & Rendah & 6 & 24 \\
\hline & & Sangat rendah & 0 & 0 \\
\hline & & Total & 27 & 100 \\
\hline \multirow[t]{5}{*}{ d } & Perizinan Sulit & Sangat Tinggi & 8 & 24 \\
\hline & & Tinggi & 12 & 48 \\
\hline & & Rendah & 6 & 24 \\
\hline & & Sangat rendah & 1 & 4 \\
\hline & & Total & 27 & 100 \\
\hline
\end{tabular}

Sumber : Data Primer, 2017. 
Aspek budaya/tradisi masyarakat menjadi kekuatan pada faktor insternal dimana diperlukan interaksi seperti antara masyarakat/konsumen dan media iklan menjadi faktor penentu mempengaruhi prilaku konsumen sebelum memutuskan untuk memilih dan membeli suatu produk (Alfitri, 2007).

Aspek peluang pada faktor eksternal meliputi aspek pasar dan pemasaran. Strategi pemasaran dapat diartikan sebagai seleksi atas pasar sasaran, menentukan posisi bersaing, dan pengembangan suatu bauran pemasaran yang efektif untuk melayani konsumen sesuai segmentasinya. Sementara dari aspek regulasi pemerintah, menurut Munarso (2016), pemerintah harus fokus terhadap pemecahan masalah untuk meningkatkan kualitas produk pertanian memerlukan pendekatan kebijakan maupun pengembangan teknologi.

Masyarakat idealnya dapat menanam, memproduksi dan menggunakan sendiri tanaman obat untuk mengatasi masalah kesehatan dengan penerapan pola kesehatan tradisiona, karena selain murah, mudah didapat dan terjangkau. Salah satu komponen penting untuk menilai perkembangan kesejahteraan ekonomi penduduk adalah menerapkan pola pengeluaran konsumsi masyarakat. Pengeluaran konsumsi masyarakat merupakan pembelajaran yang dilakukan oleh rumah tangga terhadap barang akhir atau jasa dengan tujuan untuk memenuhi kebutuhan keluarganya (Persaulian et al., 2013).

Permintaan yang tinggi pada suatu produk ditentukan juga oleh sumber daya manusia (SDM) tenaga kerja yang terlibat pada suatu usaha. Faktor yang sangat berpengaruh terhadap perspektif kinerja SDM dengan standar kinerja suatu perusahan menjadi semakin baik jika dapat memicu karyawan/SDM untuk melakukan pekerjaan terutama pada aspek produksi dengan baik dan penuh kehati-hatian (Rayadi, 2012).

Menurut Hafiz (2014), sentra industri terutama ketersediaan bahan baku memberikan jaminan kepada konsumen mengenai mutu suatu produk yang berkualitas, ditandai dengan pencantuman tanggal kadaluarsa serta memiliki kemasan yang kedap udara. Pemahaman, nilai-nilai dan aturan berperan dalam mengontrol prilaku antara pelaku usaha, pekerja (SDM) maupun konsumen secara langsung.

Atas dasar hal tersebut di atas, perlu diambil beberapa langkah kebijakan oleh Pemerintah Provinsi Lampung mendukung pengembangan tanaman obat asli Lampung meliputi:

\section{Strategi Pengembangan dan Penerapan Pen- gobatan Tradisonal dari TOAL}

Upaya Pemerintah Provinsi Lampung untuk mendukung pencapaian MDGs salah satunya melalui peningkatan kemandirian masyarakat dalam menjaga kesehatannya (Tradcom, 2012). Untuk itu diperlukan strategi pendukung agar program pengembangan dan penerapan sistem pengobatan tradisional di Provinsi Lampung dapat terlaksana dengan baik sesuai harapan, antara lain mencakup:

1. Perlu disusun regulasi formal sebagai payung hukum yang menjamin operasional ketersediaan bahan baku pengobatan tradisional yang terstandar dan bermutu, agar program saintifikasi jamu dapat berjalan sesuai harapan.

2. Komitmen Pemerintah dengan Kementerian Pertanian (tanaman biofarmaka) terhadap jaminan pasar dan kelayakan harga simplisia tanaman obat yang berpihak pada petani.

3. Tersusunnya Rancangan Peraturan Pemerintah tentang Pelayanan Kesehatan Tradisional.

4. Peranan Pemerintah bersama Kementerian Kehutanan dalam mendorong pemanfaatan lahan hutan industri melalui sistem tumpang sari mendorong pengembangan bahan baku tanaman obat tradisional asli Lampung.

5. Memprioritaskan pengembangan iptek bidang kesehatan yang dituangkan dalam kebijakan strategis pembangunan nasional.

6. Peranan Pemerintah bersama Balai Besar Pengawasan Obat dan Makanan Lampung dalam mendorong peningkatan keamanan, khasiat - manfaat dan mutu produk obat tradisional serta pengawasan pre dan post-marketing.

7. Pemerintah memfasilitasi perguruan tinggi maupun lembaga Litbang daerah untuk melakukan penelitian dan mendesiminasikan hasil-hasil penelitian yang telah dilakukan untuk diimplementasikan oleh pelaku etnomedisin maupun yang menjadi kebutuhan industri. 
Sistem Perencanaan Ketersediaan Bahan Baku Tanaman Obat Asli Lampung dan Pengawasan yang Terintegrasi.

a. Budidaya dan Konservasi Sumber Daya TOAL

\section{Sasaran:}

Tersedianya secara berkesinambungan Tanaman Obat Asli Lampung sebagai bahan baku yang memenuhi standar mutu yang dapat dimanfaatkan untuk pelayanan kesehatan dan kesejahteraan masyarakat (Pribadi, 2009).

\section{Langkah Kebijakan:}

1. Peningkatan pengembangan lintas program untuk penetapan komoditas dan pengembangan tumbuhan obat unggulan.

2. Peningkatan SDM dengan pendidikan dan pelatihan untuk menyediakan SDM kompeten dalam penyediaan bahan alam untuk bahan baku obat tradisional.

3. Peningkatan produksi mutu dan daya saing komoditas tanaman unggulan melalui Good Agriculture Practices (GAP), Good Agriculture Collecting Practices (GACP) dan Standard Operational Procedur (SOP) masing-masing komoditas.

4. Pelaksanaan survei dan evaluasi secara menyeluruh terhadap tumbuhan obat yang dimanfaatkan di Lampung dan untuk kebutuhan industri.

5. Pemetaan kesesuaian lahan yang menunjukkan daerah-daerah potensial untuk pengembangan tumbuhan obat.

6. Pelaksanaan konservasi untuk mencegah kepunahan akibat eksploitasi berlebihan maupun biopiracy melalui regulasi penelitian dan pengembangan.

7. Pemberdayaan masyarakat dalam kegiatan budidaya dan konservasi SDA.

8. Pembentukan Bank Plasma Nuftah/sumber daya genetik tumbuhan obat asli Lampung.

Lintas Program Lintas Sektor:

Balitbangda, Dinas Pertanian Prov/Kab/Kota, BPTP, Perguruan Tinggi, Industri Farmasi dan Forum Masyarakat.

\section{b. Khasiat-Manfaat Tanaman Obat Asli Lam- pung}

Sasaran: Obat tradisional yang beredar memenuhi peryaratan keamanan dan memiliki khasiat/kemanfaatan untuk pencegahan dan penyembuhan penyakit.
Langkah Kebijakan:

1. Pengembangan inventarisasi data uji praklinik.

2. Adopsi proses teknologi berdasarkan data uji pra-klinik dan data ekonomi.

3. Pengembangan uji klinik terhadap ramuan tanaman obat asli Lampung yang dimanfaatkan oleh pelaku etnomedisin.

4. Pembentukan forum komunikasi lintas sektor dan program antara Pemerintah Pusat, Provinsi, Kabupaten/Kota dan Institusi terkait.

\section{Lintas Program Lintas Sektor:}

Balitbangda, Dinas Kesehatan Prov/Kab/Kota, BPTP, Perguruan Tinggi, Pelaku Etnomedisin dan Forum Masyarakat.

\section{c. Mutu Tanaman Obat Asli Lampung}

Sasaran: Obat tradisional dari tanaman obat asli Lampung yang beredar harus memenuhi persyaratan mutu.

\section{Langkah Kebijakan:}

1. Penyusunan spesifikasi tanaman obat asli Lampung.

2. Penyusunan spesifikasi dan standar bahan baku/revisi material Medika Indonesia.

3. Penyusunan spesifikasi dan standar sediaan obat/galenik.

4. Penyusunan dan penerapan sistem mutu untuk penanganan pasca panen dan pengolahan produk.

5. Penyusunan Farmakope Obat Tradisional bahan baku tanaman obat asli Lampung.

\section{Lintas Program Lintas Sektor:}

Balitbangda, Dinas Pertanian, Dinas Kesehatan Prov/Kab/Kota, BPTP, BPOM, Industri Farmasi, Pelaku Etnomedisin dan Perguruan Tinggi.

\section{d. Aksesibilitas}

Sasaran: Sarana pelayanan kesehatan dan masyarakat dapat memperoleh Obat Tradisional yang telah memenuhi keamanan dan mutu serta terbukti khasiatnya sesuai kebutuhan dengan harga yang terjangkau.

\section{Langkah Kebijakan:}

1. Pengembangan industri Obat Tradisional di Provinsi Lampung.

2. Pengupayaan akses khusus (Special Acces) dimana Obat Tradisional dapat menyembuh- 
kan penyakit, dikarenakan secara umum obat konvensional yang ada belum terbukti efektif.

3. Pengembangan, perlindungan dan pelestarian ramuan tradisional yang terbukti bermanfaat dengan memperhatikan hak-hak pelaku etnomedisin sebagai pemilik ramuan tersebut.

4. Pemanfaatan Taman Obat Keluarga (TOGA) dalam upaya pemeliharaan kesehatan, pencegahan penyakit dan pengobatan penyakit yang sederhana.

\section{Lintas Program Lintas Sektor:}

Balitbangda, Dinas Pertanian, Dinas Perindustrian, Dinas Kesehatan Prov/Kab/Kota, Puskesmas dan Rumah Sakit, Perguruan Tinggi, Industri Farmasi dan Forum Masyarakat.

\section{e. Penggunaan yang Tepat}

Sasaran: penggunaan Obat Tradisional dalam jumlah jenis, bentuk sediaan, dosis, indikasi dan komposisi yang tepat disertai informasi yang benar, lengkap dan tidak menyesatkan (Anonim, 2017).

\section{Langkah Kebijakan :}

1. Penyediaan infromasi Obat Tradisional yang benar, lengkap dan tidak menyesatkan.

2. Pendidikan dan pemberdayakan masyarakat untuk penggunaan Obat Tradisional secara tepat dan benar.

3. Penyusunan peraturan untuk menunjang penerapan berbagai langkah kebijakan penggunaan Obat Tradisional yang tepat.

4. Pelaksanaan komunikasi, informasi dan edukasi untuk menunjang penggunaan Obat Tradisional yang tepat.

\section{Lintas Program Lintas Sektor:}

Balitbangda, Bappeda, Dinas Perdagangan, Dinas Kesehatan Prov/Kab/Kota, Puskesmas dan Rumah Sakit, Perguruan Tinggi, Industri Farmasi dan Forum Masyarakat.

\section{f. Pengawasan}

Sasaran: masyarakat terlindungi dari Obat Tradisional yang tidak memenuhi persyaratan.

\section{Langkah Kebijakan :}

1. Pelaksanaan penilaian dan pendaftaran Obat Tradisional.

2. Pelaksanaan perizinan dan sertifikasi sarana produksi.

3. Pengujian mutu dengan laboratorium yang terakreditasi.

4. Pemantauan penandaan dan promosi Obat Tradisional.

5. Pemantauan dan pengamatan pasca produksi Obat Tradisional yang diintregasikan dengan penggunaan obat medis.

6. Penilaian kembali terhadap Obat Tradisional yang beredar.

7. Peningkatan sarana dan prasarana pengawasan Obat Tradisional serta pengembangan tenaga dalam jumlah dan mutu sesuai dengan standar kompentensi.

8. Peningkatan kerjasama regional maupun internasional di bidang pengawasan.

9. Pengawasan untuk mencegah peredaran Obat Tradisional berbahan kimia dan yang diselundupkan.

10.Pengembangan Peran Serta Masyarakat (PSM) untuk melindungi dirinya sendiri terhadap Obat Tradisional sub standar melalui Kesehatan Ibu dan Anak (KIE).

\section{Lintas Program Lintas Sektor:}

Balitbangda, Bappeda, Dinas Kesehatan Prov/

Kab/Kota, BPOM, Perguruan Tinggi, Industri Farmasi dan Forum Masyarakat.

\section{g. Penelitian dan Pengembangan}

Sasaran:

1. Peningkatan penelitian di bidang Obat Tradisional untuk menunjang penerapan Kebijakan Obat Tradisional (KOTRANAS).

2. Pengembangan industri obat tradisional sebagai bagian integral dari pertumbuhan ekonomi nasional (Anonim, 2012).

\section{Langkah Kebijakan :}

1. Pelaksanaan identifikasi penelitian yang relevan dan penyusunan prioritas dengan mekanisme kerja yang erat antara penyelenggara yang mengupayakan pengembangan obat tradisional dan pelayanan kesehatan formal dengan penyelenggara penelitian dan pengembangan.

2. Peningkatan koordinasi dan sinkronisasi penyelenggaraan penelitian termasuk penetapan penelitian antar berbagai lembaga penelitian.

3. Peningkatan kerjasama internasional di bidang penelitian dan pengembangan obat tradisional. 
4. Pembinaan penyelenggaraan penelitian yang relevan dan diperlukan dalam pengembangan obat tradisional mulai dari teknologi konvensioanl sampai dengan teknologi terkini.

5. Peningkatan pembagian hasil (benefit sharing) atas perolehan Hak Kekayaan Intelektual (HKI) terhadap kearifan lokal.

6. Perlu regulasi pertukaran sumber daya alam (SDA) obat tradisional dan pemanfaatan hasil penelitian serta pengembangan obat tradisional di tingkat nasional dan regional.

7. Pembentukan aliansi strategis dalam pengembangan obat tradisional.

8. Penciptaan iklim yang kondusif bagi investasi di bidang industri obat tradisional melalui pemberian instensif kebijakan perpajakan dan perbankan serta kepastian proses perizinan.

9. Penyiapan peraturan yang tepat untuk menjamin perkembangan dunia usaha obat tradisional.

10.Peningkatan promosi obat tradisional melalui pameran dan ekspor di tingkat nasional dan internasional.

\section{Lintas Program Lintas Sektor:}

Balitbangda, Bappeda, Dinas Pertanian, Dinas Kesehatan Prov/Kab/Kota, Badan Umum Milik Daerah, Bank Indonesia, BPTP, Perguruan Tinggi, Industri Farmasi, KADIN, dan Forum Masyarakat.

\section{h. Dokumentasi dan Database}

Sasaran: Tersedianya database yang terkini dan lengkap guna menunjang obat tradisional.

\section{Langkah Kebijakan:}

1. Pengumpulan dan pengolahan data yang meliputi berbagai jenis data yang berkaitan dengan pengembangan obat tradisional.

2. Pengkajian dan analisis data ilmiah/empiris mengenai khasiat dan keamanan obat tradisional.

3. Pembuatan Bank Data yang mencakup seluruh aspek obat tradisional yang berbahan baku tanaman obat asli Lampung.

4. Pertukaran informasi secara elektronik dan dalam bentuk cetakan.

5. Pelayanan informasi termasuk informasi dan konsultasi usaha.

Lintas Program Lintas Sektor:

Balitbangda, Bappeda, Dinas Pertanian, Dinas
Perdagangan, Dinas Komunikasi dan Informasi, Dinas Kesehatan Prov/Kab/Kota.

\section{i. Pengembangan SDM}

Sasaran : tersedianya SDM yang menunjang pencapaian tujuan Kontranas.

\section{Langkah Kebijakan :}

1. Pengintregasian Kontranas dan berbagai aspek obat tradisional kedalam kurikulum pendidikan dan pelatihan tenaga terkait terutama pada pendidikan kedokteran.

2. Pengintregasian kedalam kurikulum pendidikan berkelanjutan organisasi profesi terkait.

3. Peningkatan kerjasama nasional dan internasional untuk pengembangan SDM.

\section{Lintas Program Lintas Sektor:}

Perguruan Tinggi, Tenaga/Petugas yang membidangi, Asosiasi bidang Kesehatan Tradisional, atau Forum Masyarakat.

\section{j. Pemantauan dan Evaluasi}

\section{Sasaran :}

Menunjang penerapan Kotranas melalui pembentukan mekanisme pemantauan dan evaluasi kinerja serta dampak kebijakan guna mengetahui hambatan dan penerapan strategi yang efektif.

\section{Langkah Kebijakan:}

1. Pemantauan dan evaluasi dilakukan secara berkala paling lama setiap 5 tahun.

2. Pelaksanaan dan indikator pemantauan mengikuti pedoman yang ditetapkan dan dapat bekerjasama dengan pihak lain.

3. Pemanfatan hasil pemantauan dan evaluasi untuk tindak lanjut berupa penyesuaian kebijakan.

\section{Lintas Program Lintas Sektor:}

Balitbangda, Dinas Pertanian, Dinas Kesehatan Prov/Kab/Kota, Dinas Perdagangan, BPOM dan Forum Masyarakat.

\section{KESIMPULAN}

1. Klasifikasi Persepsi Pengambil Kebijakan di Provinsi Lampung terhadap Pengembangan dan Kelayakan Usaha Tanaman Obat Asli Lampung menyatakan bahwa berdasarkan:

a. Karakteristik Responden berdasarkan jenis kelamin responden pria 64\% lebih tinggi 
dari wanita yang hanya $36 \%$; usia, $52 \%$ range usia 40-49 tahun, diikuti $40 \%$ dengan range usia 50-59 tahun, dan sisanya pada range 30-39 tahun ; pendidikan, pengambil kebijakan terbanyak S2 mencapai $56 \%, 32 \% \mathrm{~S} 1$ dan sisanya $12 \%$ berpendidikan S3; pekerjaan, sebagai PNS 92\% dan karyawan swasta sebanyak $8 \%$; jabatan, tertinggi $52 \%$ dari pejabat pengawas (setara eselon IV), 32\% pejabat administratif (setara eselon III) dan $16 \%$ menurut pejabat fungsional.

b. Faktor Internal membuktikan kekuatan penggunaan tanaman obat sebagai obat alternatif sudah membudaya atau telah menjadi tradisi masyarakat Lampung dinyatakan sebagai rating tertinggi sebanyak $40 \%$ dari responden; $52 \%$ responden menyatakan pangsa pasar untuk kalangan menengah ke bawah; 48\% responden menyatakan bahwa sumber daya manusia (SDM) dibidang tanaman obat mulai dapat disediakan dari masyarakat Lampung, yang dibuktikan beberapa perguruan tinggi negeri dan swasta maupun politeknik telah menyediakan kurikulum tentang kesehatan tradisional dan jurusan farmasi; $44 \%$ responden menyatakan bahan baku tanaman obat melimpah di Lampung. Faktor kelemahan juga merupakan bagian dari faktor internal. Dari hasil penelitian dibuktikan bahwa walaupun SDM melimpah tapi responden menyatakan $60 \%$ SDM masih kurang kreatif menciptakan varian produk obat tradisional; $72 \%$ responden menyatakan teknologi produksi masih sangat sederhana cenderung manual; pendidikan tentang kesehatan tradisional yang diaplikasikan khusus di bidang produksi tanaman obat masih rendah, umumnya $60 \%$ responden menyatakan belum diaplikasikan dengan serius; $80 \%$ responden menyatakan pengelolaan usaha tanaman obat mulai dari budidaya sampai proses pengolahan belum mengikuti Standar Operasional Prosedur (SOP) sesuai standar penggunaan bahan alam yang dipersyaratkan; dan 36\% responden menyatakan masyarakat masih mengalokasikan modal sendiri sehingga kapasitas produksi juga terbatas.

c. Faktor Eksternal 60\% responden menyatakan peluang dapat dipasarkan dalam bentuk produk olahan yang dapat dipasarkan skala domestik maupun skala nasional; $48 \%$ responden menyatakan pemerintah siap berperan sebagai regulasi untuk mendukung pengembangan tanaman obat asli Lampung melalui alokasi ke pusat-pusat kesehatan mulai dari desa (puskesmas); $68 \%$ responden menyatakan metode ini dapat memenuhi kebutuhan masyarakat khususnya ditingkat menengah ke bawah sebelum direkomendasikan penggunaan obat medis yang umumnya masih impor terkadang tidak tersedia; $56 \%$ pendapat responden bahwa pemerintah dapat menyiapkan tenaga kesehatan khusus untuk mencukupi kebutuhan di kalangan masyarakat, dapat berperan sebagai kader asuhan mandiri (asman) maupun petugas-petugas yang menguasai bidang akupresure; dan $48 \%$ dinyatakan responden jika teknis produksi memadai dapat mendorong peralihan konsumsi obat medis ke obat alternatif, sehingga masalah-masalah kesehatan dan solusi obat dapat terpecahkan. Sedangkan yang merupakan ancaman, 36\% responden menyatakan dana yang dialokasikan untuk mendukung pengembangan tanaman obat asli Lampung masih terbatas, hal ini dibuktikan dengan minimnya anggaran untuk alokasi kegiatan-kegiatan sejenis baik pada dinas teknis yang mengawal bidang budidaya sampai prosesing (Dinas Lingkup Pertanian dan Perindustrian), yang mengatur alokasi penggunaan umumnya dikalangan masyarakat (Dinas Kesehatan dan leading sektor ke bawah) maupun yang mengurus perizinan dan standardisasi melalui sosialiasi, pembinaan dan pengawasan (Dinas Perdagangan dan BBPOM); 68\% pendapat responden belum signifikan persaingan produksi maupun pemasaran produk obat tradisional yang berasal dari daerah Lampung sendiri, namun sebaliknya produk banyak berasal dari daerah lain yang SOP perizinan terstandar sehingga jika dibiarkan dapat mematikan bisnis produk obat tradisional dalam daerah yang pada kenyataannya cukup sulit mengakses perizinan dari Balai Besar Pengawasan Obat dan Makanan (BBPOM); salah satu penyebab sulitnya mengakses perizinan (menurut pengakuan $48 \%$ responden) 
bagi masyarakat yang mengembangkan usaha produksi obat tradisional umumnya dikarenakan kualitas produk maupun bahan baku masih rendah, serta rumah produksi belum memadai, hal ini dinyatakan oleh responden sebanyak $60 \%$.

2. Menentukan Strategi Pengembangan dan Penerapan Pengobatan Tradisonal serta Sistem Perencanaan Ketersedian Bahan Baku Obat Tradisional di Provinsi Lampung untuk menjadi Arah Kebijakan Nasional Mendukung Pelayanan Kesehatan Tradisonal, yang meliputi a) Budidaya dan konservasi sumber daya tanaman obat asli Lampung (TOAL), b) khasiat dan manfaat, c) mutu, d) aksesibilitas, e) cara penggunaan yang tepat, f) pengawasan, g) penelitian dan pengembangan, h) dokumentasi dan database, i) pengembangan SDM dan j) pemantauan dan evaluasi. Prioritas utama strategi sangat terkait dengan ketersediaan bahan baku hingga pemanfataan tanaman obat terutama infrastruktur pendukung, ketersediaan sumberdaya manusia.

\section{DAFTAR PUSTAKA}

Ajani, R.S. dan Ogunbiyi, K. I. 2015. Carica papaya Latex Accelerates WoundHealing in Diabetic Wistar Rats. Europian Journal of Midicinal Plants. 9 (3).

Alfitri. 2007. Budaya Konsumerisme Masyarakat Perkotaan. Majalah Empirika. Volume IX. No 01-2007.

Almos dan Pramono, 2015. Leksikon Etnomedisin dalam Pengobatan Tradisional Minangkabau. Jurnal Abitrer. Fakultas Ilmu Budaya Universitas Andalas. Padang.

Anonim. 2012. Konsep Dasar Pengembangan Obat Asli Indonesia. Modul. Materi Ujian Perpindahan Jabatan Fungsional Pengawas Farmasi dan Makanan Tingkat Terampil ke Ahli bagi Pegawai Negeri Sipil Badan POM RI.

Anonim. 2017. Tanaman Herbal Indonesia. Ebook. Didownload tanggal 22 September 2017. 16:00 WIB

BPS Kabupaten Lampung Utara. 2015. Statistik Daerah Lampung Utara.
BPS Provinsi Lampung. 2013. Provinsi Lampung Dalam Angka. http://lampungutarakab.bps.go.id/website/pdf_publikasi/ Statistik-Daerah-Lampung-Utara-2015. pdf

Hafiz, T.M. 2014. Hubungan Tingkat Modal Sosial Terhadap Tingkat Pendapatan Pelaku UKM. Jurnal Mahasiswa Sosiologi. Volume 03 No 2 hal : 1-17.

Hidayati, W. 2011. Pengaruh Ekstrak Batang Brotowali terhadap Demam Typhoid pada Tikus Putih. SKRIPSI. Program Studi Pendidikan Biologi Jurusan Pendidikan MIPA FKIP Universitas Jember.

Juarez-Rojop IE. Diaz-ZAgoya JC. Ble-Castillo JL, Miranda-Osorio PH, Castell-Rodriguez AE. Tovilla-Zarate CA. 2012. Hypoglicemic Effect of Carica papaya leaves in streptozotocin-induced diabetic rats. Complementaory and Alternative Medicine. 12.

Munarso, J. 2016. Penanganan Pasca Panen untuk Peningkatan Mutu dan Daya Saing Komoditas Kakao. Jurnal Litbang Pertanian Volume 35. Nomor 3 September 2016. Hal : 111-120.

Peraturan Pemerintah Nomor 103 Tahun 2014 tentang Pelayanan Kesehatan Tradisonal.

Persaulian, B. Aimon, H. Anis, A. 2013. Analisis Konsumsi Masyarakat di Indonesia. Jurnal Kajian Ekonomi, Januari 2013, Vol I. No.02 Hal : 1-23.

Pribadi E., R., 2009 dalam Pasokan dan Permintaan Tanaman Obat Indonesia serta Arah Penelitian dan Pengembangannya, Balai Penelitian Tanaman Obat dan Aromatik Bogor. Perspektif Vol. 8 No.1 Juni 2009. Hlm 52-64. ISSN : 1412-8004.

Rangkuti., F. 2006. Analisis SWOT, Teknik Membedah Kasus Bisnis. Jakarta (Indonesia). Gramedia Pustaka Utama.

Rayadi. 2012. Faktor Sumber Daya Manusia yang Meningkatkan Kinerja Karyawan dan Perusahaan di Kalbar. ISSN : 16939093. Volume 8, Nomor 2, Juni 2012 hal 
: 114-119.

Tradkom. 2012. Newsletter. Bakti Husada. Direktorat Bina Pelayanan Kesehatan Tradisional, Alternatif dan Komplementer. Direktorat Jenderal Bina Gizi Kesehatan Ibu dan Anak. Kementerian Kesehatan Republik Indonesia. Jakarta.

Ttipathi, S. Suzuki J.Y. Carr JB, Mc.Quate GT, Ferreire SA, Manshardt RM. 2011. Nutritional Composition of Rainbow papaya, the first commercialized transgenic fruit crop. Journal of Food Composition and Analysis. 24 (2).

Undang-Undang Nomor 36 Tahun 2009 tentang Kesehatan. Pasal 48. Kementerian Kesehatan Republik Indonesia. Jakarta.

World Health Organization. 2013. Book. Traditional Medicine Strategy 2014-2023. 